\title{
Transposition of the great arteries
}

Matthew Baillie writing in the 18th century described transposition of the great arteries as 'a singular malformation, in which the pulmonary artery arises from the left ventricle and the aorta from the right ventricle'. ${ }^{1} \mathrm{He}$ was probably unable to envisage any means whereby the anatomical defect could be overcome, though it is clear he well understood the physiological implications.

\section{The clinical problem}

Infants with transposition are cyanosed and will become increasingly so in the absence of intervention. So great is the cyanosis that most will die in the first two months of life if untreated. ${ }^{2}$ The presence of certain associated lesions lessens the cyanosis and may improve the natural prognosis, by allowing mixing between pulmonary and systemic circulations. The result is a higher arterial oxygen saturation, but the price is a higher pulmonary blood flow and an increased, indeed very high risk of developing pulmonary vascular obstructive disease. This, in the infant with transposition and a large ventricular septal defect, may become irreversible before the first birthday.

A severely cyanotic infant fails to thrive; feeding is difficult because of disinterest and fatigue. These children are irritable and have a very limited capacity to exert themselves. Motor developmental milestones are delayed, and the increased haematocrit carries with it the danger of cerebrovascular accidents. Cerebral abscess is not infrequent and severe debility can follow the minor common ailments. If the additional lesion produces a high pulmonary blood flow, dyspnoea with profuse sweating on exertion and on feeding will be added symptoms. Overt cardiac failure may supervene as pulmonary resistance falls during the early months of life.

\section{Balloon atrial septostomy}

This is mandatory in all infants with transposition, and should be undertaken as soon as practicable after recognition of the cardiac cause of cyanosis. The procedure should carry virtually no risk. The creation of the atrial septal defect allows a stable haemodynamic state to be achieved. The infant will feed well, thrive, and maintain an arterial oxygen saturation at $60-70 \%{ }^{3}$ The haemoglobin concentration will run at $15-18 \mathrm{~g} \%$.

In month 3 or 4 of life re-evaluation of the infant's haemodynamic state should be undertaken, at least including a two dimensional echocardiogram. If a ventricular septal defect or ductus arteriosus were found to be additional lesions at the time of balloon atrial septostomy it may be necessary to include cardiac catheterisation and angiocardiography.

During the second year of life after balloon septostomy alone, cyanosis may increase with a reduction in the general well being of the child. The additional presence of mild subpulmonary obstruction confers the best survival, but from the second year survival falls at $10 \%$ per annum. ${ }^{4}$ Earlier increase in cyanosis warrants complete re-evaluation as this suggests changing pulmonary blood flow characteristics.

\section{Rearrangement of atrial flow}

It is clear that balloon atrial septostomy provides effective early palliation, but definitive correction of the blood flow pattern should not be delayed. The age at which this is achieved has gradually fallen so that our current recommendations place the timing of interatrial rearrangement of blood flow by the Mustard or Senning technique at 6-12 months of age. ${ }^{5}$

This unit favours the Senning technique when feasible, as it has the clear advantage of providing unobstructed venous pathways and avoids the use of foreign material. There is no appreciable difference in the frequency of dysrhythmias between the Mustard procedure, as currently performed, and the Senning technique, but it has also been established that a tendency to minor conduction abnormalities above and within the atrioventricular node is inherent in transposition. ${ }^{6}$

The additional presence of a small ventricular septal defect does not change the management. It may not be necessary to close such defects as there is a high spontaneous closure rate, but even a small persistent ductus arteriosus should be ligated.

Larger defects (ventricular septal defect or patent ductus arteriosus) may require modification of this plan of management, particularly in view of the tendency to develop pulmonary vascular obstructive disease, but also because of cardiac failure. The defects should be closed at the time of interatrial 
repair, possibly earlier than 6 months of age and certainly before 12 months. An alternative approach may be indicated for large defects.

\section{The 'switch' operation}

The logical approach to correct the malformation of transposition is to relocate the great arteries above the appropriate ventricle-pulmonary artery over the right ventricle, aorta over the left. One major technical factor is to move the coronary arteries so that their origin is still from the effective aorta. The next point to consider is the function of the left ventricle, as it will be generating less than systemic pressure in simple transposition, but once the aorta arises from this ventricle it must assume the pressure and flow characteristics of the normal systemic arterial ventricle. Finally, there should be no obstruction within the outflow of the left ventricle.

Selection becomes important and while many patients with simple transposition will be precluded, those with important ventricular septal defects or a large ductus may be better managed by this operation than by rearranging the atrial flow. ${ }^{7}$ The ventricular septal defect would be closed or the ductus ligated.

Attempts have been made to 'prime' the left ventricle to assume its role as a systemic arterial ventricle in cases of simple transposition where the left ventricular pressure is less than systemic. This may be attempted by banding the pulmonary artery, by creating a systemic artery-pulmonary artery shunt, or by a combination of both these methods. ${ }^{8}$ In some neonates it may be possible to undertake the switch procedure successfully as the primary procedure.

\section{Prognosis of the infant with transposition}

For the infant with simple transposition whose cardiac disease is recognised early there should be virtually no mortality associated with the investigation and balloon atrial septostomy. He should not run an appreciable risk before further operation within the first year of life (in the absence of intercurrent illness). It is clear that rearrangement of atrial flow, even within the first year of life, should be achieved with a survival rate greater than $95 \%$. Long term survival is dependent on the function of the right ventricle as the dominant factor, pulmonary vascular disease being avoided by appropriate management in infancy. It is now clear that the tricuspid valve function is adequate to sustain the systemic work load, provided it is a competent valve before operation. Late failure of the valve relates to right ventricular dysfunction, or disruption of the valve by infection. ${ }^{9}$

Arrhythmias were a major complication in the early series, but a better understanding of the anatomy of the conduction tissue coupled with improvements in technique have reduced these to a minimum. It has been clear that some atrial arrhythmias are inherent in transposition, and are not produced or influenced by operation.

The functional status after interatrial repair is good; to the parents a normal effort tolerance seems to be achieved. To the cardiologist the mean for the group lies along or just below the expected tolerance for the height and age as judged on a bicycle ergometer. ${ }^{10}$ One concern to the parents of girls may be allayed by the increasing number of successful pregnancies reported.

Survival after the 'switch' operation cannot yet be predicted with the same precision, as the 'long term' is, to date, much shorter. The immediate results are comparable to the best interatrial repair but the initial mortality is higher. The advantages become apparent with major ventricular septal defects where it is clear that the switch operation is preferable. ${ }^{7}$ It must be remembered that in transposition the left ventricular performance differs from the normal left ventricle antenatally and up to the time of operation-are we justified in assuming that from then on it will perform as a normal left ventricle? It is still to be shown that it will perform better for longer than the right ventricle after interatrial repair.

\section{Conclusion}

Matthew Baillie commented on this 'singular malformation' in anatomical terms. It is submitted that transposition is also a singular nalformation in physiological terms, and that neither interatrial repair, nor the switch operation may resolve all the physiological abnormalities.

\footnotetext{
References

1 Baillie M. The morbid anatomy of some of the most important parts of the human body. 2nd edition. London: J Johnson and G Nicol, 1797:38.

2 Liebman J, Callum L, Belloc NB. Natural history of transposition of the great arteries. Circulation 1969;40:247-62.

3 Tynan M. Haemodynamic effects of balloon atrial septostomy in infants with transposition of the great arteries. $\mathrm{Br}$ Heart $\mathrm{J}$ 1972;34:791-4.

4 Leanage R, Agnette A, Graham G, Taylor JFN, Macartney FJ. Factors influencing survival after balloon atrial septostomy for complete transposition of great arteries. $\mathrm{Br}$ Heart $\mathrm{J}$ 1981;45:559-72.
} 


\section{Taylor}

5 Stark J. Concordant transposition-Mustard operation. In: Stark J, de Leval M, eds. Surgery for congenital heart defects. London, New York: Grune and Stratton, 1983:331-44.

${ }^{6}$ Deanfield J, Camm J, Stark J, et al. Arrhythmias before and after intra-atrial repair of transposition. Proceedings of the 20th annual meeting of the Association of European Paediatric Cardiologists, Bordeaux, May 1983.

7 Williams WG, Freedom RM, Culham G, et al. Early experience with arterial repair of transposition. Ann Thorac Surg $1981 ; 32: 8-15$.

8 Yacoub M, Bernhard A, Lange P, et al. Clinical and hemodynamic results of the two-stage anatomic correction of simple transposition of the great ateries. Circulation 1980;62:(Suppl 1):190-6.
${ }^{9}$ Schmitz JP, Taylor JFN, Graham GR, Stark J. Late results of Mustard operation for transposition of the great arteries. Proceedings of the 7th European Congress of Cardiology 1976. ${ }^{10}$ Stark J, Weller P, Leanage R, et al. Late results of surgical treatment of transposition of the great arteries. Adv Cardiol $1980 ; 27: 254-65$

JAMES F N TAYLOR

The Thoracic Unit, The Hospital for Sick Children, Great Ormond Street, London WC1N 3JH 